\title{
Genetic Heterogeneity in the Cerebrohepatorenal (Zellweger) Syndrome and Other Inherited Disorders with a Generalized Impairment of Peroxisomal Functions
}

\section{A Study Using Complementation Analysis}

\author{
S. Brul," A. Westerveld, ${ }^{*}$ A. Strijland,* R. J. A. Wanders," A. W. Schram," H. S. A. Heymans," R. B. H. Schutgens," \\ H. van den Bosch," and J. M. Tager* \\ ${ }^{*}$ Laboratory of Biochemistry, University of Amsterdam, 1105 AZ Amsterdam; ${ }^{\ddagger}$ Division of Cell Biology and Genetics, Erasmus \\ University, 3000 DR Rotterdam; ' Department of Pediatrics, University Hospital, University of Amsterdam, 1105 AZ Amsterdam; \\ "Laboratory of Biochemistry, University of Utrecht, 3584 CH Utrecht, The Netherlands
}

\begin{abstract}
We have used complementation analysis after somatic cell fusion to investigate the genetic relationships among various genetic diseases in humans in which there is a simultaneous impairment of several peroxisomal functions. The activity of acyl-coenzyme A:dihydroxyacetonephosphate acyltransferase, which is deficient in these diseases, was used as an index of complementation. In some of these diseases peroxisomes are deficient and catalase is present in the cytosol, so that the appearance of particle-bound catalase could be used as an index of complementation. The cell lines studied can be divided into at least five complementation groups. Group 1 is represented by a cell line from a patient with the rhizomelic form of chondrodysplasia punctata. Group 2 consists of cell lines from four patients with the Zellweger syndrome, a patient with the infantile form of Refsum disease and a patient with hyperpipecolic acidemia. Group 3 comprises one cell line from a patient with the Zellweger syndrome, group 4 one cell line from a patient with the neonatal form of adrenoleukodystrophy, and group 5 one cell line from a patient with the Zellweger syndrome. We conclude that at least five genes are required for the assembly of a functional peroxisome.
\end{abstract}

\section{Introduction}

Peroxisomes are organelles bounded by a single membrane and are characterized by the presence of catalase and at least one $\mathrm{H}_{2} \mathrm{O}_{2}$-producing oxidase. They occur in virtually all eukaryotic cells. During the last decade, the importance of peroxisomes in the metabolism of mammalian cells has become increasingly evident. The functions assigned to peroxisomes now include the $\beta$-oxidation of very-long-chain fatty acids (1-3), the biosynthesis of ether phospholipids (4) and bile acids $(5,6)$, the oxidation of prostaglandins $(7)$ and, in humans, the catabolism of glyoxylate $(8,9)$.

In 1973 Goldfischer et al. (10) discovered that morphologically distinguishable peroxisomes are absent in liver and kidney of patients with the cerebrohepatorenal (Zellweger) syn-

Address reprint requests to Dr. Tager.

Received for publication 22 September 1987 and in revised form 10 December 1987.

J. Clin. Invest.

(c) The American Society for Clinical Investigation, Inc. 0021-9738/88/06/1710/06 \$2.00

Volume 81, June 1988, 1710-1715 drome (ZS). ${ }^{1}$ Since that time several genetic disorders have been recognized in which peroxisomal functions are impaired (for review, see references 11-13). In some of the disorders a single peroxisomal enzyme is deficient, whereas in others more than one peroxisomal function is impaired.

In one category of diseases with multiple deficiencies there is an impairment of some, but not all, peroxisomal functions. So far, the only disease described in this category is the rhizomelic form of chondrodysplasia punctata $(\operatorname{RCDP})(14,15)$, the biochemical characteristics of which can be summarized as follows. First, the enzymes acyl-coenzyme A (CoA):dihydroxyacetonephosphate acyltransferase (DHAP-AT) and alkyldihydroxyacetonephosphate synthase are deficient, so that the biosynthesis of plasmalogens is impaired $(14,15)$. Secondly, it can be inferred that there is a deficiency of phytanic acid oxidase since there is an accumulation of phytanic acid in body fluids (15). Thirdly, peroxisomal thiolase is present as a 44-kD protein (A. W. Schram and R. J. A. Wanders, unpublished observations; W. W. Chen, P. A. Watkins, and H. W. Moser, personal communication), which is the $M_{\mathrm{r}}$ of the precursor form of the enzyme $(16,17)$. However, peroxisomes are present, as indicated by the fact that the catalase activity in fibroblasts is particle-bound (15). In this disease, there is no abnormality in the peroxisomal oxidation of fatty acids (R. J. A. Wanders, unpublished observations).

The second category of diseases with multiple dysfunctions comprises disorders with a generalized deficiency of peroxisomal enzymes and a virtually complete absence of morphologically distinguishable peroxisomes. The cerebrohepatorenal (Zellweger) syndrome (ZS), the infantile form of Refsum disease (IRD), the neonatal form of adrenoleukodystrophy (NALD), and hyperpipecolic acidemia (HPA) fall within this category. The biochemical features of these diseases are summarized in Table 5 of Schutgens et al. (13).

We have used complementation analysis after somatic cell fusion of cultured skin fibroblasts to determine the genetic relationships among the diseases with a partial or generalized impairment of peroxisomal functions. The results described in this article, some of which have been communicated in a preliminary form (18-20), indicate that the cell lines studied can be divided into five complementation groups, so that at least

1. Abbreviations used in this paper: DHAP-AT, dihydroxyacetonephosphate acyltransferase; HPA, hyperpipecolic acidemia; IRD, infantile form of Refsum disease; NALD, neonatal form of adrenoleukodystrophy; RCDP, rhizomelic form of chondrodysplasia punctata; ZS, Zellweger syndrome. 
five genes must be involved in the assembly of a functional peroxisome.

In an independent study, Roscher et al. (21) have identified four complementation groups in fibroblasts from patients with ZS and NALD.

\section{Methods}

Cell lines. Cultured skin fibroblasts were obtained from patients with the cerebrohepatorenal syndrome (cell line W78/515: Tegelaers et al. [22]; cell line CJD85AD: Barth et al. [23]; cell line RICK86AD: Barth et al. [24]; cell line KRZW84/118: Wanders et al. [25]; cell line GOM85AD: Wanders et al. [25]; cell line GRO87AD: from a patient [to be described elsewhere] with all biochemical abnormalities associated with ZS [13]); RCDP (cell line MCHE85AD: Heymans et al. [15]); NALD (cell line AAL85AD: Kelly et al. [26]), HPA (cell line GM3605: Thomas et al. [27]), and IRD (cell line BOV84AD: Poll-Thé et al. [28]).

Materials. Ham's F-10 Medium and Dulbecco's modified Eagle's medium (DME) were obtained from Gibco (Glasgow, UK). Polyethylene glycol (PEG) $\left(M_{\mathrm{r}} 1,000\right)$ was purchased from E. Merck (Darmstadt, FRG), enzymes from Boehringer (Mannheim, FRG), and radiochemicals from the Radiochemical Centre (Amersham, UK). All other reagents were of analytical grade.

Fusion procedure. Cells to be fused were cocultivated for $1 \mathrm{~d}$ before the actual fusion in a 1:1 mixture of Ham's F-10 and DME supplemented with $10 \%$ (vol/vol) fetal calf serum in $25-\mathrm{cm}^{2}$ culture flasks (Falcon Labware, Oxnard, CA) under $5 \% \mathrm{CO}_{2} / 95 \%$ air. The amount of cells of each fusion partner was chosen such that confluency was reached within $24 \mathrm{~h}$ and the cultures contained an equal number of cells of each cell line. The subsequent steps of the fusion procedure were carried out in the absence of fetal calf serum. A monolayer of the mixture of fibroblasts was washed three times with Ham's F10/DME (1:1). Fusion was carried out by the addition to the monolayer of 0.6 $\mathrm{ml}$ of a solution consisting of $41 \%$ (vol/vol) PEG and $8.75 \%$ (vol/vol) DMSO in Ham's F10/DME (1:1) followed 2 min later by $0.6 \mathrm{ml} 25 \%$ PEG in Ham's F10/DME (1:1). The PEG suspension was diluted twice at 2-min intervals with $4 \mathrm{ml}$ of Ham's F10/DME (1:1). The resulting suspension was subsequently aspirated and the fused cells were washed once with Ham's F10/DME (1:1) before further culture of the hybrids in Ham's F10/DME (1:1) supplemented with $10 \%$ (vol/vol) fetal calf serum under $5 \% \mathrm{CO}_{2} / 95 \%$ air. The fusion efficiency (percentage of total nuclei in fused cell cultures present in multinucleate cells) was always in the range of $60-90 \%$.

Assessment of complementation. The occurrence of complementation was tested in three ways. First, acyl-CoA:DHAP-AT activity was measured at intervals $24-120 \mathrm{~h}$ after fusion according to (29). Secondly, the percentage of particle-bound catalase was determined at intervals 24-96 $\mathrm{h}$ after fusion according to (30). Thirdly, the presence of sedimentable catalase was investigated $48 \mathrm{~h}$ after fusion by means of Percoll density gradient fractionation essentially according to Oude Elferink et al. (31). In the gradient fractions the following marker enzymes were assayed: $\beta$-hexosaminidase (lysosomes) (31) was assayed with the corresponding 4-methylumbelliferyl substrate; lactate dehydrogenase (cytosol) was assayed in a medium (final volume $2 \mathrm{ml}$; final pH 7.4) containing $50 \mathrm{mM}$ potassium phosphate, enzyme preparation, $0.2 \mathrm{mM} \mathrm{NADH}$, and $1 \mathrm{mM}$ pyruvate; catalase activity was measured polarographically in a medium (final volume $280 \mu \mathrm{l}$; final $\mathrm{pH} 7.4$ ) containing $50 \mathrm{mM}$ potassium phosphate, $0.1 \%$ (vol/vol) Triton X-100, enzyme preparation, and $10 \mathrm{mM}$ sodium perborate. Protein was determined according to Lowry et al. (32).

\section{Results}

\section{Measurements of acyl-CoA:DHAP-AT}

The activity of acyl-CoA:DHAP-AT in control fibroblasts ranged from 7.7 to $11.9 \mathrm{nmol} / 2 \mathrm{~h} \cdot \mathrm{mg}$ protein. In the mutant cell lines the activity was between 0.1 and $2 \mathrm{nmol} / 2 \mathrm{~h} \cdot \mathrm{mg}$ protein.

The results of representative fusion experiments involving cell lines from patients with ZS, NALD, RCDP, IRD, and HPA are shown in Figs. 1 and 2. In the combinations shown in Fig. 1 there was a gradual two- to threefold increase in DHAPAT activity after fusion. In the cocultivation controls little, if any, increase was observed. These cell lines clearly complement each other. In contrast, there was no significant increase in DHAP-AT activity in fusion experiments involving the cell lines ZS1, IRD, and HPA, as shown in Fig. 2. In self fusion control experiments no significant increase in DHAP-AT activity was found; representative experiments are shown in Fig. 3.

The results of the fusion experiments are summarized in Table I. Thus the cell lines fall into at least five complementation groups (Table II).

\section{Subcellular localization of catalase after complementation}

Digitonin titration studies. Recently it has been shown that the intracellular localization of catalase in fibroblasts can be established by measuring the latency of the enzyme after a titration of the cells with digitonin (30). The method is based upon the fact that digitonin forms stoichiometric complexes with cholesterol, that this leads to permeabilization of membranes, and that the various cellular membranes differ in cholesterol content. We used this method to investigate the subcellular localization of catalase after fusion of cells from ZS, IRD, NALD, and HPA patients; these diseases are characterized by a deficiency of functional peroxisomes (see for reviews references 11-13) and particle-bound catalase is absent. However, the enzyme is not deficient, but is localized in the cytosol ( 30 , $33,34)$.

The results of a typical digitonin titration experiment involving ZS2 and IRD cells are shown in Fig. 4. Only a small amount of digitonin $(<40 \mu \mathrm{g} / \mathrm{ml})$ was needed to release all latent catalase enzyme activity in cocultivated ZS2 and IRD cells. This indicates that in ZS and IRD fibroblasts catalase is not localized in peroxisomes $(30,34)$. Fused ZS2 and IRD cells showed a different behavior. In the heterokaryons much higher concentrations of digitonin $(>200 \mu \mathrm{g} / \mathrm{ml})$ were required to abolish catalase latency completely. These concentrations were in the range of those necessary to release latency of peroxisomal catalase in control fibroblasts (26). Thus, the results indicate that in ZS2 $\times$ IRD hybrid cells catalase-positive particles (presumably peroxisomes) were formed. Comparable results were obtained using other combinations of $\mathrm{ZS}$, IRD, NALD, and HPA fibroblasts that showed complementation with regard to DHAP-AT (results not shown).

Percoll density gradient centrifugation studies. Another means of studying the subcellular localization of catalase is to use Percoll density gradient fractionation. Fig. 5 shows the distribution of marker enzymes for the cytosol, lysosomes, and peroxisomes, after fractionation of cell lines from a control subject, two complementary mutant cell lines (ZS1 and ZS2), and the heterokaryons obtained after fusion of the two cell lines. The apparent density of the catalase-containing particles in the heterokaryons was about the same as found for control cells. No sedimentable catalase was formed after cocultivation of the cells or in the self-fusion controls (results not shown). Essentially the same results were obtained using other fusion combinations of ZS, IRD, NALD, and HPA fibroblasts that 


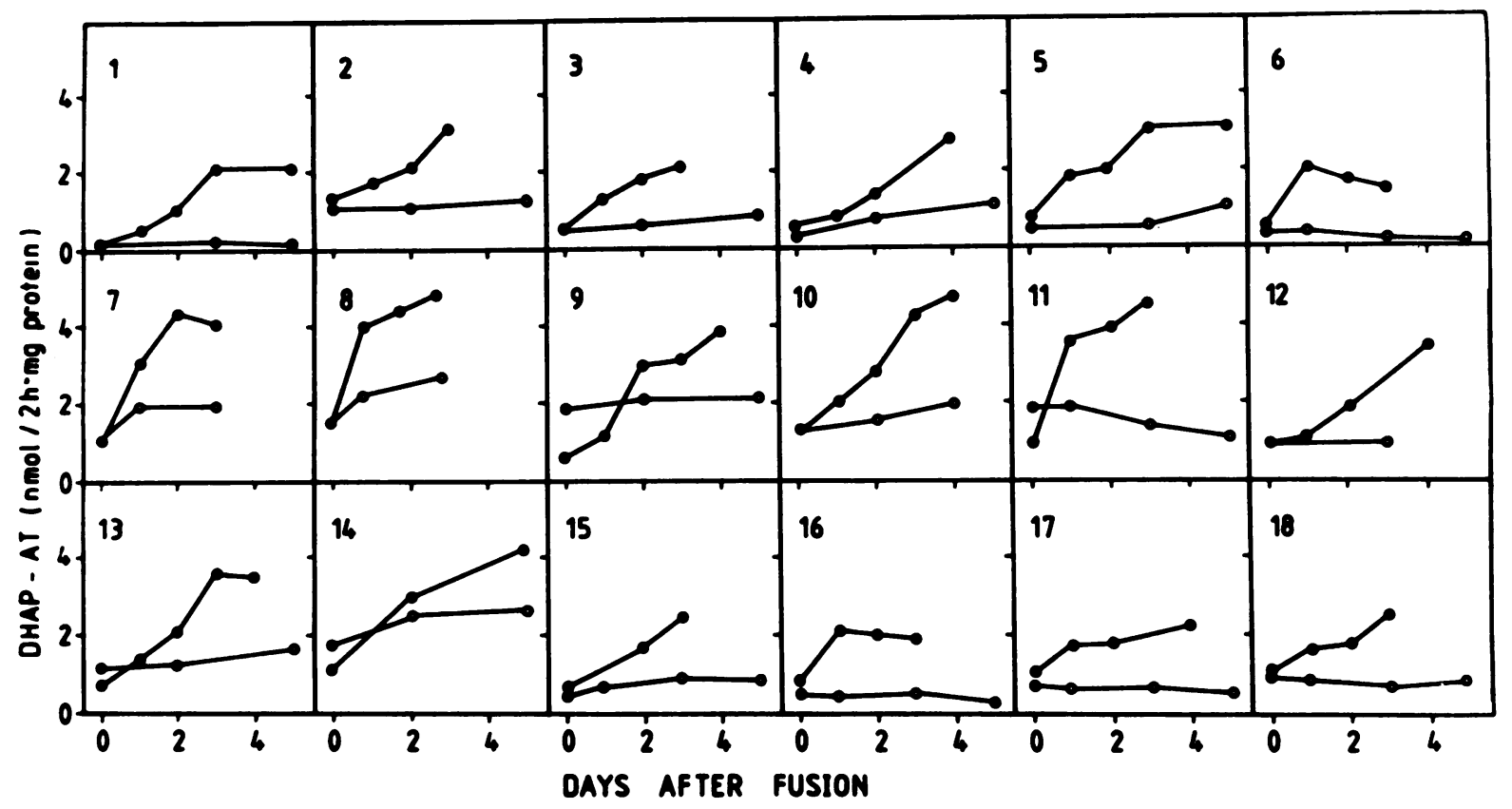

Figure 1. Complementation analysis of fibroblasts from patients with peroxisomal disorders. DHAP-AT activity was measured at intervals after fusion ( $\bullet$ ) or cocultivation (O) of ZS1 (cell lines: W78/515, CJD85AD, RICK86AD, KRZW84/118), ZS2 (cell line:

GOM85AD), ZS3 (cell line: GR087AD), IRD, HPA, RCDP, and NALD fibroblasts. The cells were fused using PEG as described in Methods. Experiments using ZS1 cell line W78/515 are shown; ex-

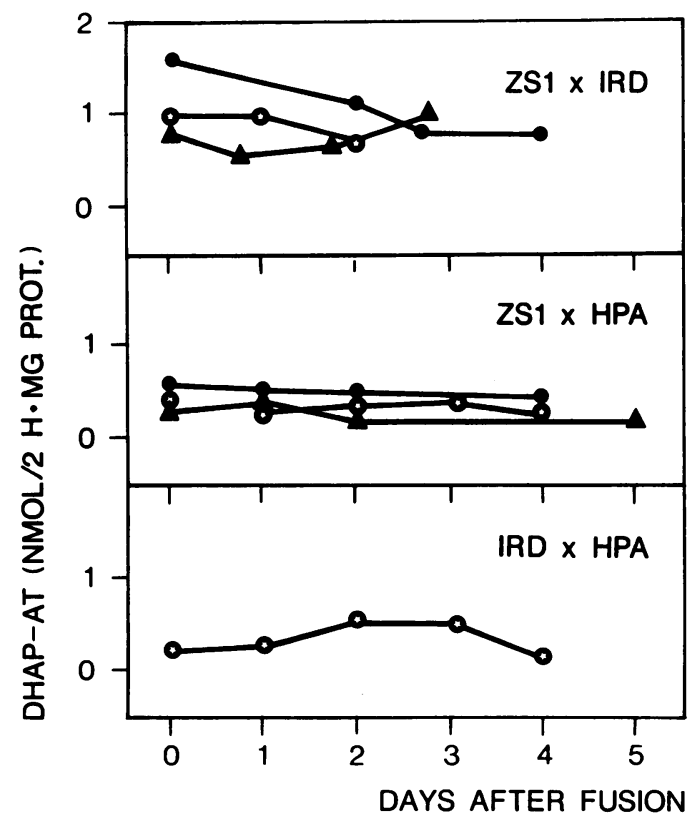

Figure 2. Lack of complementation between certain Zellweger cell lines (ZS1) and IRD and HPA fibroblasts. DHAP-AT activity was measured at intervals after fusion between ZS1 (cell lines: W78/515, CJD85AD, RICK86AD, KRZW84/118), IRD, and HPA fibroblasts. For experimental details see Methods. The experiments shown were performed using ZS1 cell line W78/515; exactly analogous results were obtained with the other ZS1 cell lines. The results of three different experiments are presented for the ZS1 $\times$ HPA and ZS $1 \times$ IRD fusions. actly analogous results were obtained with the other ZS1 cell lines. Panel 1, ZS2 $\times$ ZS1; 2, ZS2 $\times$ HPA; 3, ZS2 $\times$ IRD; 4, ZS2 $\times$ NALD; $5, \mathrm{ZS} 2 \times \mathrm{RCDP} ; 6, \mathrm{ZS} 2 \times \mathrm{ZS} 3 ; 7, \mathrm{RCDP} \times \mathrm{ZS} 1 ; 8$, RCDP $\times$ IRD; 9, RCDP $\times$ HPA; 10, RCDP $\times$ NALD; 11, RCDP $\times$ ZS3; 12, NALD $\times$ ZS1; 13, NALD $\times$ IRD; 14, NALD $\times$ HPA; $15, \mathrm{NALD} \times \mathrm{ZS} 3 ; 16, \mathrm{ZS} 3 \times \mathrm{ZS} 1 ; 17, \mathrm{ZS} 3 \times \mathrm{IRD} ; 18, \mathrm{ZS} 3 \times$ HPA.

showed complementation with regard to DHAP-AT (results not shown).

Taken together, the results of the catalase latency and sedimentability studies show that after complementation particles

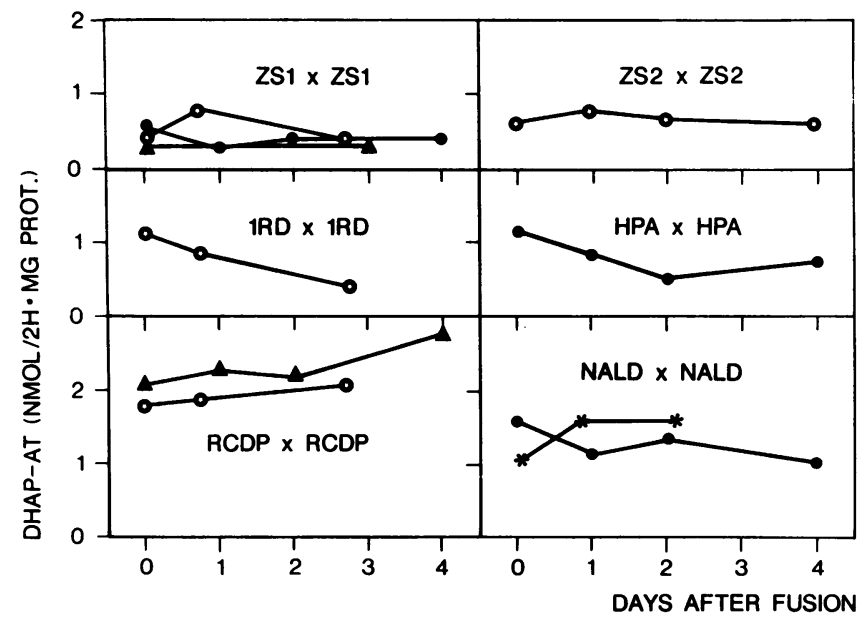

Figure 3. Self-fusion control experiments. DHAP-AT activity was measured at intervals after self-fusion of ZS1 (cell lines: W78/515, CJD85AD, RICK86AD, KRZW84/118), ZS2 (cell line:

GOM85AD), IRD, HPA, RCDP, and NALD fibroblasts. For experimental details see Methods. The experiments shown were performed using ZS1 cell line W78/515; exactly analogous results were obtained with the other ZS1 cell lines. The results of three different experiments are given for the ZS1 self-fusions, and of two different experiments for the RCDP and NALD self-fusions. 
Table I. Complementation Analysis of Peroxisomal Disorders

\begin{tabular}{lccccccc}
\hline & RCDP & ZS1 & ZS2 & ZS3 & IRD & HPA & NALD \\
\hline RCDP & - & + & + & + & + & + & + \\
ZS1 & + & - & + & + & - & - & + \\
ZS2 & + & + & - & + & + & + & + \\
ZS3 & + & + & + & - & + & + & + \\
IRD & + & - & + & + & - & - & + \\
HPA & + & - & + & + & - & - & + \\
NALD & + & + & + & + & + & + & - \\
\hline
\end{tabular}

Summary of the results shown in Figs. 1-3. + denotes complementation, and - denotes lack of complementation.

arise that are able to incorporate catalase. These particles behave like normal peroxisomes in latency and sedimentability studies.

\section{Discussion}

Our complementation studies clearly show that at least five genes are involved in the biogenesis of a functional peroxisome. Gene 1 (complementation group 1) encodes a protein necessary for the expression of DHAP-AT, alkyl DHAP synthase, and phytanic acid oxidase; this protein could represent a receptor necessary for incorporation of the enzymes into a peroxisome. Genes 2, 3, 4, and 5 (complementation groups 2, 3,4 and 5) code for proteins necessary for the assembly of functional peroxisomes; the proteins could be either membrane components and/or cytosolic factors. Since Roscher et al. (21) have identified two complementation groups within cell lines from patients with NALD, an additional gene may be involved in the assembly of peroxisomes.

It has been suggested earlier by Goldfischer and Reddy (12) that there may be different subgroups of ZS. The results reported in this article provide objective evidence that this is, indeed, the case. However, it should be noted that the cell lines in group 2 were obtained from patients diagnosed clinically as having different disorders. Thus cell line GM 3605, which was obtained from a cell bank, was derived from a patient described as having HPA (27). According to our data HPA, in this patient at least, is not a separate disease but is one of the subgroups of ZS.

At least three possible reasons for the absence of complementation between the cell lines in group 2 can be considered. First, the disorders might be caused by allelic mutations. Secondly, they may represent phenotypic variations of the same

Table II. Complementation Groups in Diseases with a Partial or Generalized Impairment of Peroxisomal Functions

\begin{tabular}{cl}
\hline $\begin{array}{c}\text { Complementation } \\
\text { group }\end{array}$ & \multicolumn{1}{c}{ Phenotypes } \\
\hline 1 & RCDP \\
2 & ZS1, IRD, HPA \\
3 & ZS2 \\
4 & NALD \\
5 & ZS3 \\
\hline
\end{tabular}



Figure 4. Increase in particle-bound catalase after fusion of complementary cell lines. Percentage of particle-bound catalase was measured at intervals after fusion (๑) or cocultivation (o) of ZS2 (cell line: GOM85AD) and IRD fibroblasts. The fibroblasts were fused using PEG as described in Methods. At various days after fusion or cocultivation, the percentage of particle-bound catalase was determined by means of digitonin titration.

mutation. Thirdly, the absence of complementation after fusion of two cell lines might be due to the absence of preexisting peroxisomes, since it is now generally accepted $(35,36)$ that new peroxisomes arise by budding or fission of preexisting ones (see references 18, 19, 37 for a discussion). Experiments with cytoplasts are at present being carried out to test this possibility.

The fact that complementation could also be assessed by measuring catalase latency and sedimentability in heterokaryons derived from cells lacking peroxisomes has a number of important implications. First, the appearance of catalase-positive particles after complementation is a direct demonstration that organelles arise with characteristics similar to those of normal peroxisomes. Secondly, the catalase latency measurements offer the possibility of performing an accurate kinetic study of the complementation process; the results of these studies will be communicated elsewhere. Thirdly, the fact that the presence of DHAP-AT activity is accompanied by the presence of catalase-positive particles provides indirect evidence that a peroxisome is needed for the expression of DHAP-AT activity.

In conclusion, we have unequivocally demonstrated that genetic heterogeneity exists within the group of peroxisomal disorders characterized by a generalized impairment of perox- 


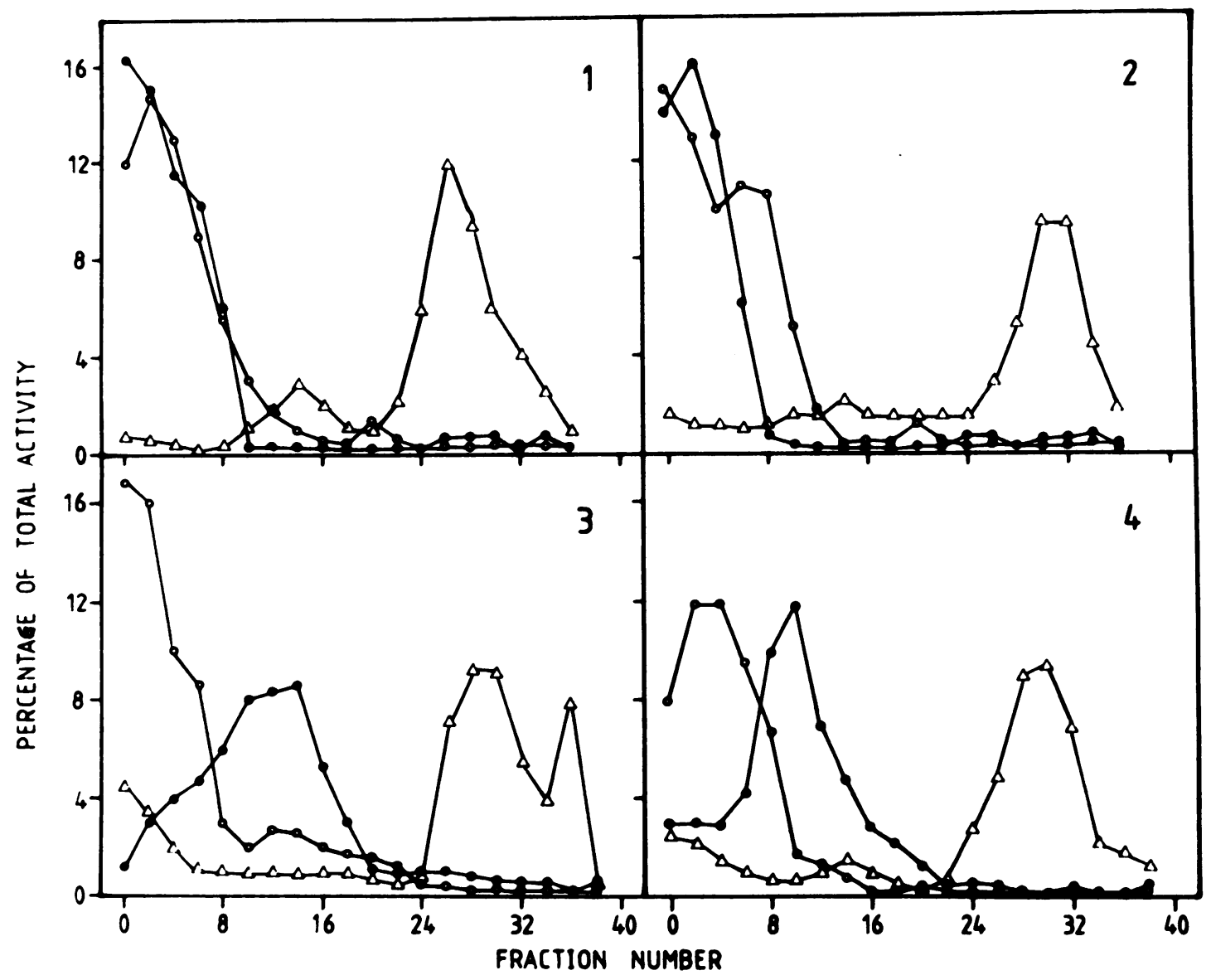

Figure 5. Distribution of marker enzymes after Percoll density gradient fractionation of control fibroblasts, two complementary Zellweger cell lines, and heterokaryons formed by fusion of the two mutant cell lines. The mutant cell lines used were W78/515 (ZS1) and GOM85AD (ZS2); the cells were fused using PEG as described in

Methods, and the heterokaryons were harvested $48 \mathrm{~h}$ later. After fractionation of the cells on a Percoll density gradient, lactate dehydrogenase (cytosol, $-0-0-$ ) $\beta$-hexosaminidase (lysosomes, $-\Delta-\Delta-$ ), and catalase (peroxisomes, $-\bullet-\bullet-$ ) were measured in the gradient fractions. Panel 1, ZS1; 2, ZS2; 3, control; 4, ZS1 $\times$ ZS2.

isomal functions, even within the clinically relatively homogeneous ZS. A similar conclusion has been reached by Roscher et al. (21). With regard to the observed genetic heterogeneity within ZS, it is of interest to consider the medical background of the patients under study. Interestingly, the ZS1 cell lines (complementation group 2) were all derived from patients ranging in age from 2 to $6 \mathrm{yr}$. In contrast, the other ZS cell lines, ZS2 and ZS3 (complementation groups 3 and 5) were obtained from patients who died at the age of 3 and 5 months, respectively. Thus, it is clear that mutations in two different genes can lead to the same clinical and biochemical phenotype.

Further studies are needed to assess the function of the various gene products necessary for the assembly of a normal peroxisome. Isolation and characterization of the genes and of their products should in the future increase our insight into the molecular background of various hereditary peroxisomal disorders.

\section{Acknowledgments}

The authors are grateful to Wil Tegelaers, Bwee-Tien Poll-Thé, JeanMarie Saudubray, Peter Barth, M. Liberman, R. A. Chalmers, and Hugo Moser for supplying cell lines, to Gerrit-Jan Romeyn for expert technical assistance, to Desiree Saelman for her help in some of the initial experiments, and to Wendy van Noppen for her help in the preparation of the manuscript. The authors are particularly grateful to Piet Borst for his continued interest and encouragement and for his critical comments and suggestions.

This study was supported by a grant from the Netherlands Organisation for Pure Scientific Research (ZWO) under the auspices of the Netherlands Foundation for Medical and Health Research (MEDIGON).

\section{References}

1. Lazarow, P. B., and C. De Duve. 1976. A fatty acyl-CoA oxidizing system in rat liver peroxisomes: enhancement by clofibrate, a hypolipidemic drug. Proc. Natl. Acad. Sci. USA. 73:2043-2046.

2. Bremer, J. 1977. Carnitine and its role in fatty acid metabolism. Trends. Biochem. Sci. 2:207-209.

3. Singh, I., A. E. Moser, S. Goldfischer, and H. W. Moser. 1984. Lignoceric acid is oxidized in the peroxisome: implications for the Zellweger cerebro-hepato-renal syndrome and adreno-leukodystrophy. Proc. Natl. Acad. Sci. USA. 81:4203-4207.

4. Hajra, A. K., and J. E. Bishop. 1982. Glycerolipid biosynthesis in peroxisomes via the acyl dihydroxyacetonephosphate pathway. Ann. N.Y. Acad. Sci. 386:170-182.

5. Pedersen, J. I., and J. Gustafsson. 1980. Conversion of 
$3 \alpha, 7 \alpha, 12 \alpha$-trihydroxy-5 $\beta$-cholestanoic acid into cholic acid by rat liver peroxisomes. FEBS (Fed. Eur. Biochem. Soc.) Lett. 121:345-348.

6. Hagey, L. R., and S. K. Krisans. 1982. Degradation of cholesterol to propionic acid by rat liver peroxisomes. Biochem. Biophys. Res. Commun. 107:834-841.

7. Diczfalusy, U., S. E. H. Alexson, and J. I. Pedersen. 1987 Chain-shorting of prostaglandin $\mathrm{F}_{2} \alpha$ by rat liver peroxisomes. Biochem. Biophys. Res. Commun. 144:1206-1213.

8. Noguchi, T., and Y. Takada. 1979. Peroxisomal localization of alanine: glyoxylate aminotransferase in human liver. Arch. Biochem. Biophys. 196:645-647.

9. Danpure, C. J., and P. R. Jennings. 1986. Peroxisomal alanine: glyoxylate aminotransferase deficiency in primary hyperoxaluria type I. FEBS (Fed. Eur. Biochem. Soc.) Lett. 201:20-24.

10. Goldfischer, S., C. L. Moore, A. B. Johnson, A. J. Spiro, M. P. Valsamis, H. K. Wisniewski, R. H. Ritch, W. T. Norton, I. Rapin, and L. M. Gartner. 1973. Peroxisomal and mitochondrial defects in the cerebrohepatorenal syndrome. Science (Wash. DC). 182:62-64.

11. Kelly, R. I. 1983. Review: the cerebro-hepato-renal syndrome of Zellweger. Morphologic and metabolic aspects. Am. J. Med. Genet. 16:503-517.

12. Goldfischer, S., and J. K. Reddy. 1984. Peroxisomes (microbodies) in cell pathology. Int. Rev. Exp. Pathol. 26:45-84.

13. Schutgens, R. B. H., H. S. A. Heymans, R. J. A. Wanders, H. van den Bosch, and J. M. Tager. 1986. Review: peroxisomal disorders. A newly recognized group of genetic diseases. Eur. J. Pediatr. $144: 430-440$.

14. Heymans, H. S. A., J. W. E. Oorthuijs, G. Nelck, R. J. A. Wanders, and R. B. H. Schutgens. 1984. Rhizomelic chondrodysplasia punctata: another peroxisomal disorder. N. Engl. J. Med. 313:187188.

15. Heymans, H. S. A., J. W. E. Oorthuijs, G. Nelck, R. J. A. Wanders, K. P. Dingemans, and R. B. H. Schutgens. 1986. Peroxisomal abnormalities in rhizomelic chondroplasia punctata. $J$. Inherited Metab. Dis. 9:329-331.

16. Furuta, S., T. Hashimoto, S. Miura, M. Mori, and M. Tatibana. 1982. Cell-free synthesis of the enzymes of peroxisomal $\beta$-oxidation. Biochem. Biophys. Res. Commun. 105:639-646.

17. Fujiki, Y., R. A. Rachubinski, R. M. Mortensen, and P. B. Lazarow. 1985. Synthesis of 3-ketoacyl-CoA thiolase of rat liver peroxisomes on free polyribosomes as a larger precursor: induction of thiolase mRNA activity by clofibrate. Biochem. J. 226:697-704.

18. Wanders, R. J. A., D. Saelman, H. S. A. Heymans, R. B. H. Schutgens, A. Westerveld, B. T. Poll-Thé, J. M. Saudubray, H. ván den Bosch, A. Strijland, A. W. Schram, and J. M. Tager. 1986. Genetic relation between the Zellweger syndrome, infantile Refsum's disease and rhizomelic chondrodysplasia punctata. $N$. Engl. J. Med. 314:787788.

19. Tager, J. M., A. W. Schram, A. Strijland, R. J. A. Wanders, and A. Westerveld. 1986. More on Zellweger syndrome, infantile Refsum's disease and rhizomelic chondrodysplasia punctata. N. Engl. J. Med. 315:767.

20. Tager, J. M., A. Westerveld, A. Strijland, A. W. Schram, R. B. H. Schutgens, H. van den Bosch, and R. J. A. Wanders. 1987. In Peroxisomes in Biology and Medicine. H. D. Fahimi and H. Sies, editors. Springer-Verlag, Berlin. 353-357.

21. Roscher, A., S. Höfler, G. Höfler, E. Paschke, and F. Paltauf 1986. Neonatal adrenoleukodystrophy (NALD) and cerebrohepatorenal syndrome (CHRS): genetic complementation analysis of impaired peroxisomal plasmalogen biosynthesis. Abstracts of the 24th Annual Symposium of the Society for the Study of Inborn Errors of Metabolism. Amersfoort, The Netherlands. 03.

22. Tegelaers, W. H. H., J-.U. Walter, J. Müller-Hocker, and P. Borst. 1983. Deficiency of plasmalogens in the cerebro-hepato-renal (Zellweger) syndrome. Eur. J. Pediatr. 142:10-15.
23. Barth, P. G., R. B. H. Schutgens, R. J. A. Wanders, H. S. A. Heymans, A. B. Moser, H. W. Moser, E. M. Bleeker-Wagemakers, K. Jansonius-Schultheuss, M. Derix, and G. F. Nelck. 1987. A sibship with a mild variant of Zellweger syndrome. J. In̈herited Metab. Dis. In press.

24. Barth, P. G., R. B. H. Schutgens, J. A. J. M. Bakkeren, K. P. Dingemans, H. S. A. Heymans, A. C. Douwes, and J. M. Van der Klei-van Moorsel. 1985. A milder variant of Zellweger syndrome. Eur. J. Pédiatr. 144:338-342.

25. Wanders, R. J. A., W. Smit, H. S. A. Heymans, R. B. H. Schutgens, P. G. Barth, H. Schierbeek, G. P. A. Smit, R. Berger, H. Przyrembel, T. S. Eggelte, J. M. Tager, P. D. Maaswinkel-Mooy, A. C. B. Peters, L. A. H. Monnens, J. A. J. M. Bakkeren, J. M. F. Trijbels, E. J. P. Lommen, and N. Beganovic. 1987. Age-related accumulation of phytanic acid in plasma from patients with the cerebrohepato-renal (Zellweger) syndrome. Clin. Chim. Acta. 166:45-56.

26. Kelly, R. I., N. S. Datta, W. B. Dobijns, A. K. Hajra, A. B. Moser, M. J: Noetzel, E. H. Zackai, and H. W. Mbser. 1986. Neonatal adrenoleukodystrophy: new cases, biochemical studies, and differentation from Zellweger and related peroxisomal polydystrophy syndromes. Am. J. Med. Genet. 23:869-901.

27. Thomas, G. H., H. A. Haslam, M. O. Gatschaw, J. A. Capute, L. Neidergoud, and T. L. Ranson. 1975. Hyperpipecolic acidemia associated with hepatomegaly, mental retardation, optic nerve dysplasia and progressive neurological disease. Clin. Genet. 8:376-382.

28. Poll-Thé, B. T., J. M. Saudubray, H. Ogier, R. B. H. Schutgens, R. J. A. Wanders, G. Schrakamp, H. van den Bosch, J. M. F. Trijbels A. Poulos, H. W. Moser, J. van Eldere, and H. J. J. Eijssen. 1986. Infantile Refsum's disease: biochemical findings suggesting a generalized dysfunction of peroxisomes. J. Inherited Metab. Dis. 9:169-174.

29. Schutgens, R. B. H., G. J. Romeyn, R. J. A. Wanders, H. van den Bosch, G. Schrakamp, and H. S. A. Heymans. 1984. Deficiency of acyl-CoA: dihydroxyacetonephosphate acyltransferase in patients with Zellweger (cerebro-hepato-renal) syndrome. Biochem. Biophys. Res. Commun. 120:179-184.

30. Wanders, R. J. A., M. Kos, B. Roest, A. J. Meijer, G. Schrakamp, H. S. A. Heymans, W. H. H. Tegelaers, H. van den Bosch, R. B. H. Schutgens, and J. M. Tager. 1984. Activity of peroxisomal enzymes and intracellular distribution of catalase in Zellweger syndrome. Biochem. Biophys. Res. Commun. 123:1054-1061.

31. Oude Elferink, R. P. J., J. van Doorn-van Wakeren, A. Strijland, A. J. J. Reuser, and J. M. Tager. 1985. Biosynthesis and intracellular transport of $\alpha$-glucosidase and cathepsin $\mathrm{D}$ in normal and mutant human fibroblasts. Eur. J. Biochem. 153:55-63.

32. Lowry, O. H., N. J. Rosenbrough, A. L. Farr, and R. J. Randell. 1951. Protein measurements with the Folin phenol reagent. J. Biol. Chem. 193:265-275.

33. Lazarow, P. B., V. Black, H. Shio, Y. Fujiki, A. K. Hajra, N. S. Datta, B. S. Bangaru, and J. Danas. 1985. Zellweger syndrome: biochemical and morphological studies on two patients treated with clofibrate. Pediatr. Res. 19:1356-1364.

34. Wanders, R. J. A., R. B. H. Schutgens, G. Schrakamp, H. van den Bosch, J. M. Tager, A. W. Schram, T. Hashimoto, B. T. Poll-Thé, and J. M. Saudubray. 1986. Infantile Refsum's disease: deficiency of catalase-containing particles (peroxisomes), alkyldihydroxyacetone phosphate synthase and peroxisomal $\beta$-oxidation enzyme proteins. Eur. J. Pediatr. 145:172-175.

35. Lazarow, P. B., and Y. Fujiki. 1985. Biogenesis of peroxisomes. Annu. Rev. Cell. Biol. 1:489-530.

36. Borst, P. 1986. Review: how proteins get into microbodies (peroxisomes, glyoxysomes, glycosomes). Biochim. Biophys. Acta. 66:179-203.

37. Goldfischer, S. 1986. More on Zellweger syndrome, infantile Refsum's disease and rhizomelic chondrodysplasia punctata. N. Engl. J. Med. 315:767. 